\title{
Long-term complete response to gefitinib after treatment termination in a patient with recurrent post-operative EGFR- mutated lung adenocarcinoma: case report and literature review
}

\author{
Kenji Watanabe ${ }^{1}$, Naoki Haratake ${ }^{1}$, Tomoyoshi Takenaka ${ }^{1}$, Taichi Nagano ${ }^{1}$, Yuka Oku ${ }^{1}$, Keisuke Kosai ${ }^{1}$, \\ Yuki Ono ${ }^{1}$, Mikihiro Kohno ${ }^{1}$, Yoshinao Oda ${ }^{2}$ \\ ${ }^{1}$ Department of Surgery and Science, Graduate School of Medical Sciences, Kyushu University, Fukuoka, Japan; ${ }^{2}$ Department of Anatomic \\ Pathology, Graduate School of Medical Sciences, Kyushu University, Fukuoka, Japan \\ Correspondence to: Tomoyoshi Takenaka, MD, PhD. Department of Surgery and Science, Graduate School of Medical Sciences, Kyushu University, \\ 3-1-1 Maidashi, Higashi-ku, Fukuoka 812-8582, Japan. Email: ttake@surg2.med.kyushu-u.ac.jp.
}

\begin{abstract}
Non-small-cell lung cancer (NSCLC) with epidermal growth factor receptor (EGFR) mutations is highly sensitive to EGFR-tyrosine kinase inhibitor (EGFR-TKI). However, few cases of advanced NSCLC completely cured by EGFR-TKIs have been reported. We present an extremely rare case of lung adenocarcinoma that was completely cured by gefitinib administration. A 36-year-old Japanese woman was diagnosed with clinical Stage IIIB (T2N3M0) lung adenocarcinoma originating from the left upper lobe in April 2006. After the two cycles of chemotherapy, it was down-staged to ycStage IA (T1N0M0). She underwent a thoracotomy with left upper lobectomy, pulmonary angioplasty, and mediastinal nodal dissection in July 2006 [ypStage IIIA (T3N1M0)]. Eighteen months later, she was found to have lymphadenopathy of the right supraclavicular nodes. Fine needle aspiration cytology of the lymph node indicated adenocarcinoma. She started gefitinib therapy for recurrent lung cancer with EGFR mutation (exon 19 deletion) in January 2008. Four months afterward, computed tomography (CT) showed her right supraclavicular nodes had shrunk dramatically. Treatment with gefitinib was continued. Thereafter, no disease progression was observed throughout her approximately 8-year gefitinib treatment, and gefitinib was terminated in November 2016. Although the patient received no other treatment, she has suffered no recurrence in the 4 years since. A review of the literature, including our case, is also presented.
\end{abstract}

Keywords: Lung cancer; epidermal growth factor receptor (EGFR); gefitinib; complete response; case report

Submitted Jul 01, 2021. Accepted for publication Aug 20, 2021.

doi: $10.21037 /$ tcr-21-1140

View this article at: https://dx.doi.org/10.21037/tcr-21-1140

\section{Introduction}

Non-small-cell lung cancer (NSCLC) with epidermal growth factor receptor (EGFR) mutations is highly sensitive to EGFR-tyrosine kinase inhibitor (EGFR-TKI). However, few cases of advanced NSCLC completely cured by EGFR-TKIs have been reported. Here, we report a case of a post-operative recurrence of EGFR-mutated lung adenocarcinoma that achieved a clinically complete response to gefitinib that has continued for 4 years after terminating gefitinib treatment. We also present a literature review. We present the following case in accordance with the CARE reporting checklist (available at https://dx.doi. org/10.21037/tcr-21-1140).

\section{Case presentation}

A 36-year-old Japanese woman was diagnosed with clinical Stage IIIB (T2N3M0) lung adenocarcinoma originating from the left upper lobe in April 2006. Computed tomography (CT) showed a $30-\mathrm{mm}$ mass in the left upper lobe, enlarged right tracheobronchial nodes and left supraclavicular nodes. Mediastinoscopy with biopsy 

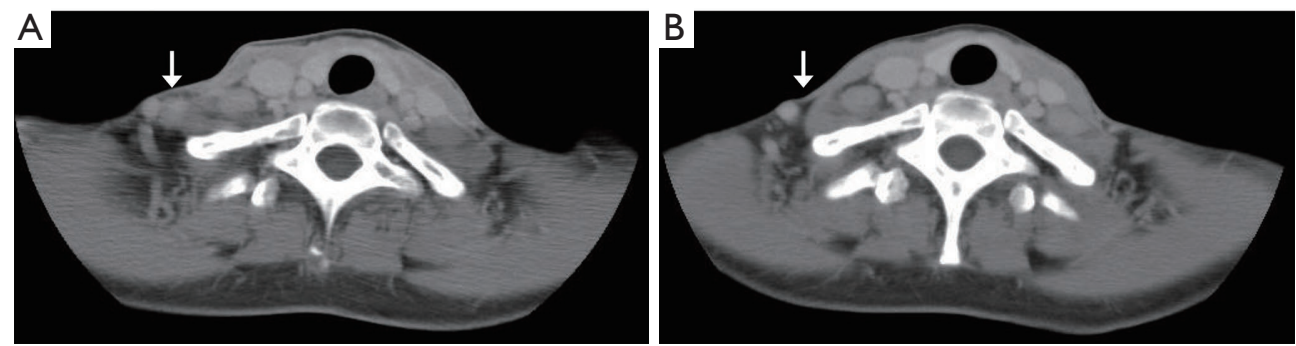

Figure 1 Cervical CT before and after initiating gefitinib. (A) Before initiating gefitinib, post-operative recurrence in the right supraclavicular nodes (shown by arrow) was observed. (B) After initiating gefitinib, the right supraclavicular nodes extremely shrank (shown by arrow). CT, computed tomography.

from the left supraclavicular nodes revealed metastatic adenocarcinoma; N3 disease was confirmed. After the two cycles of chemotherapy (cisplatin + gemcitabine + vinorelbine), it was down-staged to ycStage IA (T1N0M0). She underwent a thoracotomy with left upper lobectomy, pulmonary angioplasty, and mediastinal nodal dissection in July 2006 [ypStage IIIA (T3N1M0)]. Approximately 11 months after the surgery, post-operative oligo-recurrence of lung cancer with left supraclavicular nodes metastasis was observed. A left supraclavicular and both sides of cervical nodal dissection was performed in July 2007.

In December 2007, she was found to have lymphadenopathy of the right supraclavicular nodes. As fine-needle aspiration cytology showed adenocarcinoma, she was diagnosed with post-operative recurrence. The right supraclavicular nodes are observed $15 \mathrm{~mm}$ in size, and no other sites of recurrence were observed in CT (Figure 1A). EGFR mutation (exon 19 deletion) was detected in the primary tumor specimens, so gefitinib was initiated in January 2008. Four months later, CT showed the right supraclavicular nodes had shrunk dramatically (Figure 1B), and the treatment with gefitinib was continued. Gefitinib initiation was reduced to once every 2 days in November 2011 due to seborrheic dermatitis (grade 3). After that, no disease progression was observed throughout the gefitinib treatment, for approximately 5 years. Positron emission tomography-CT showed no recurrence in June 2014. Gefitinib was terminated in November 2016 at the patient's wish. She received no other anti-tumor treatment. In May 2021, CT showed no signs of tumor progression or new lesion. As no recurrence has been observed for the 4 years since terminating gefitinib, gefitinib treatment has apparently cured her recurrent NSCLC.

All procedures performed in studies involving human participants were in accordance with the ethical standards of the institutional and/or national research committee(s) and with the Helsinki Declaration (as revised in 2013). Written informed consent was obtained from the patient for publication of this case report and accompanying images. A copy of the written consent is available for review by the editorial office of this journal.

\section{Discussion}

We present here an extremely rare case of post-operative recurrence of $E G F R$-mutated lung adenocarcinoma that was evidently cured with gefitinib therapy. The right supraclavicular metastatic lymph nodes, in which adenocarcinoma was found with fine needle aspiration, shrank remarkably with gefitinib administration. Even after terminating gefitinib, disease progression has not been observed for 4 years.

To our knowledge, only two other cases of EGFRmutated lung adenocarcinoma have achieved complete responses to EGFR-TKI with long-lasting progressionfree survival (PFS) after terminating EGFR-TKI treatment (Table 1) $(1,2)$. All of these cases were post-operative recurrences with exon-19 deletions. According to the results of the WJTOG3405 trial, overall survival of patients with recurrent lung cancers was better than that of patients with Stage IIIB/IV disease (3), which may reflect their differences in tumor volume. Post-operative recurrences are usually diagnosed at routine follow-ups, at intervals of several months after resections; treatment for recurrent disease therefore starts with lower tumor burden than that for Stage IIIB/IV disease. Thus, in the current case, the low tumor burden might have been associated with the dramatic response to EGFR-TKI. Adjuvant osimertinib significantly improved disease-free survival among patients with EGFR mutation-positive NSCLC in ADAURA trial [not related (NR) vs. 19.6 months; hazard ratio for disease recurrence 
Table 1 Published case reports of clinically complete responses of EGFR-mutated NSCLC after terminating EGFR-TKI treatment

\begin{tabular}{|c|c|c|c|c|c|c|c|c|c|}
\hline Case & $\begin{array}{l}\text { Authors } \\
\text { (published year) }\end{array}$ & Age & Gender & r Diagnosis & rTNM & $\begin{array}{l}\text { EGFR } \\
\text { subtype }\end{array}$ & $\begin{array}{l}\text { EGFR-TKI, } \\
\text { administration period }\end{array}$ & $\begin{array}{l}\text { PFS after terminating } \\
\text { EGFR-TKI }\end{array}$ & Refs no. \\
\hline 1 & $\begin{array}{l}\text { Kuwata et al. } \\
\text { [2016] }\end{array}$ & 75 & M & $\begin{array}{l}\text { Post-operative } \\
\text { recurrence in the right } \\
\text { supraclavicular nodes }\end{array}$ & TON3MO & Ex 19 del & Gefitinib, 18 months & $\begin{array}{l}\text { More than } 120 \\
\text { months }\end{array}$ & (1) \\
\hline 2 & $\begin{array}{l}\text { Yamanaka et al. } \\
\text { [2019] }\end{array}$ & 73 & $\mathrm{~F}$ & $\begin{array}{l}\text { Post-operative liver } \\
\text { metastases }\end{array}$ & $\begin{array}{l}\text { TONOM1c } \\
\text { (HEP) }\end{array}$ & Ex 19 del & Afatinib, 24 months & More than 18 months & (2) \\
\hline
\end{tabular}

EGFR, epidermal growth factor receptor; NSCLC, non-small-cell lung cancer; EGFR-TKI, EGFR-tyrosine kinase inhibitor; rTNM, recurrence tumor-node-metastasis classification; HEP, hepatic metastasis; ex 19 del, exon 19 deletion; PFS, progression-free survival.

or death, $0.17 ; 99.06 \%$ confidence interval (CI), 0.11 to $0.26 ; \mathrm{P}<0.001]$ (4). This also might suggest that tumor burden have a relationship with the efficacy of EGFR-TKI. Whether the EGFR subtype (exon 19 deletion) affected the result is unclear. No pattern was observed with respect to recurrence sites, EGFR-TKI type, or EGFR-TKI administration period.

Discontinuation of EGFR-TKI can cause some patients to suffer rapid disease progression within a short time, which has been called a disease flare (5). In the current case, disease flare was not observed, and complete response has persisted for 4 years after stopping gefitinib. This suggests that the tumor may have completely disappeared. Whether disease flare will occur in cases of complete response is unclear; however, when terminating an EGFR-TKI, switching to other treatments or careful follow-up is clearly advised. As predictive factors for successful discontinuation of EGFR-TKIs have not been determined, further research is warranted.

\section{Conclusions}

We report a patient with recurrent NSCLC that harbored activating $E G F R$-mutations, who had a long-enduring complete response after terminating gefitinib. Further research is needed to identify factors that indicate EGFRTKI can be successfully discontinued.

\section{Acknowledgments}

The authors would like to thank Edanz Group (https://enauthor-services.edanz.com/ac) for editing a draft of this manuscript.
Funding: None.

\section{Footnote}

Reporting Checklist: The authors have completed the CARE reporting checklist. Available at https://dx.doi. org/10.21037/tcr-21-1140

Peer Review File: Available at https://dx.doi.org/10.21037/ tcr-21-1140

Conflicts of Interest: All authors have completed the ICMJE uniform disclosure form (available at https://dx.doi. org/10.21037/tcr-21-1140). The authors have no conflicts of interest to declare.

Ethical Statement: The authors are accountable for all aspects of the work in ensuring that questions related to the accuracy or integrity of any part of the work are appropriately investigated and resolved. All procedures performed in studies involving human participants were in accordance with the ethical standards of the institutional and/or national research committee(s) and with the Helsinki Declaration (as revised in 2013). Written informed consent was obtained from the patient for publication of this case report and accompanying images. A copy of the written consent is available for review by the editorial office of this journal.

Open Access Statement: This is an Open Access article distributed in accordance with the Creative Commons Attribution-NonCommercial-NoDerivs 4.0 International License (CC BY-NC-ND 4.0), which permits the non- 
commercial replication and distribution of the article with the strict proviso that no changes or edits are made and the original work is properly cited (including links to both the formal publication through the relevant DOI and the license). See: https://creativecommons.org/licenses/by-nc-nd/4.0/.

\section{References}

1. Kuwata T, Yoneda K, Kobayashi K, et al. Achievement of cure with gefitinib in advanced lung adenocarcinoma harboring an activating EGFR mutation: a case report. Case Rep Oncol 2016;9:565-7.

2. Yamanaka Y, Seki Y, Ishikawa T, et al. Long-lasting response to afatinib that persisted after treatment discontinuation in a case of $E G F R$-mutated lung

Cite this article as: Watanabe $\mathrm{K}$, Haratake $\mathrm{N}$, Takenaka T, Nagano T, Oku Y, Kosai K, Ono Y, Kohno M, Oda Y. Longterm complete response to gefitinib after treatment termination in a patient with recurrent post-operative EGFR-mutated lung adenocarcinoma: case report and literature review. Transl Cancer Res 2021;10(11):5010-5013. doi: 10.21037/tcr-21-1140 adenocarcinoma. BMJ Case Rep 2019;12:227383.

3. Yoshioka H, Shimokawa M, Seto T, et al. Final overall survival results of WJTOG3405, a randomized phase III trial comparing gefitinib versus cisplatin with docetaxel as the first-line treatment for patients with stage IIIB/IV or postoperative recurrent $E G F R$ mutation-positive nonsmall-cell lung cancer. Ann Oncol 2019;30:1978-84.

4. Wu YL, Tsuboi M, He J, et al. Osimertinib in resected EGFR-mutated non-small-cell lung cancer. $\mathrm{N}$ Engl J Med 2020;383:1711-23.

5. Chaft JE, Oxnard GR, Sima CS, et al. Disease flare after tyrosine kinase inhibitor discontinuation in patients with EGFR-mutant lung cancer and acquired resistance to erlotinib or gefitinib: implications for clinical trial design. Clin Cancer Res 2011;17:6298-303. 